\title{
Older Adults' Engagement in Senior University Lectures and the Effect of Individual Motivations
}

\author{
Tobias Peter Ackermann ${ }^{1,2,3}$ and Alexander Seifert ${ }^{1,2 *}$ \\ ${ }^{1}$ Center for Gerontology, University of Zurich, Zurich, Switzerland, ${ }^{2}$ URPP Dynamics of Healthy Aging, University of Zurich, Zurich, \\ Switzerland, ${ }^{3}$ Interfaculty Center for Educational Research, University of Bern, Bern, Switzerland
}

Among older adults, engagement in education can potentially have positive effects on cognition and psychological well-being and can prevent social isolation. The aim of this study is to investigate the role of individual motivations specific to older learners that underlie the frequency of participation at a senior university and how health or socioeconomic dimensions may affect the possibilities for participation. With data on participants from the senior university program at the University of Zurich ( $N=811)$, we show that greater individual motivations regarding different aspects of learning have an effect on the frequency of lecture attendance, while other life circumstances do not.

OPEN ACCESS

Edited by:

Marvin Formosa,

University of Malta, Malta

Reviewed by:

Bernhard Schmidt-Hertha, Ludwig Maximilian University of

Munich, Germany

Cecilia Bjursell,

Jönköping University, Sweden

Vera Gallistl,

University of Vienna, Austria

*Correspondence:

Alexander Seifert

alexander.seifert@zfg.uzh.ch

Specialty section:

This article was submitted to Educational Psychology,

a section of the journal

Frontiers in Education

Received: 04 August 2020 Accepted: 01 February 2021

Published: 09 March 2021

Citation: Ackermann TP and Seifert A (2021) Older Adults' Engagement in Senior University Lectures and the Effect of Individual Motivations.

Front. Educ. 6:591481.

doi: 10.3389/feduc.2021.591481 However, the findings show that when different forms of motivation are compared, instrumental motivation-meaning that the intention to use the gained knowledge now or in the future is responsible for the participant's learning aspirations -is the only motivation that significantly increases lecture attendance. Hence, we conclude that to increase people's engagement in this specific form of education in later life and to intensify lecture attendance, these programs should meet participants expectations.

Keywords: learning, older adults, motivation, education, participation, health

\section{INTRODUCTION}

In Switzerland, 32\% of the population between the ages of 65 and 75 are engaged in some form of education after retirement, and they most frequently attend courses that are not work related (BFS, 2016). Because of the increase in retirees' participation in nonformal education (institutionalized educational programs in addition to formal education within the process of lifelong learning), it is not surprising that an increasing number of universities and other educational institutions are adapting their services by providing courses that are designed for older adults who are or will soon be retired. Universities have begun to adapt their services to the aging population in programs often referred to as "university for senior citizens," "senior university," or "university of the third age." These are designed mostly as an additional offer (Formosa, 2019) to meet the desire for lifelong learning (Knapper and Cropley, 2000; Formosa, 2014). Tabatabaei and Roostai (2014) display the findings from research on senior universities: participants of senior universities show good levels of life quality and better mental and physical health (Mitchell et al., 1997; Zielińska-Więczkowska et al., 2011). The senior university (SU) at the University of Zurich offers an educational curriculummainly in the form of open lectures-with an emphasis on academic quality that is open to all older adults, with an average membership fee (registration fee).

To date, the research regarding people's engagement in education in later life shows that these forms of education and training have various positive effects on general health. Namely, 
improvements in health related to education are found in the enhancement of cognitive capabilities (Clare and Woods, 2004; Park et al., 2007; Chan et al., 2016; Vaportzis et al., 2017) (subjective) well-being (Hammond, 2004; Narushima et al., 2013; Jenkins and Mostafa, 2015), and social networks (Hayward et al., 2015). In addition, continuous participation enhances the positive effects of education on people, allowing them to feel more autonomous again and more fulfilled (Narushima et al., 2018). Mitchell et al. (1997) report that members of American seniors in universities score better on average regarding their general, physical, and mental health than a peer group not going to university.

As shown, engaging in activities such as those provided by the SU increases the physical and psychological well-being of older adults, and higher or continuous attendance increases these positive effects. Hence, it is crucial to understand the individual motivational factors that underlie course attendance and which of them can increase attendance. Research on the motivations and educational engagement of older adults is rooted in the work of Houle (1961). Others have further developed this approach by redefining the theoretical arguments or implementing empirical research strategies. Boshier (1991), elaborating on Houle's typology, designed the Education Participation Scale (EPS), which exists in different abbreviated forms and consists of seven motivational factors in its current form. Hence, various studies look at the motivations in the context of older adults' engagement in education (e.g., Kim and Merriam, 2004; Kitiashvili and Tasker, 2016; Lin, 2020). Further, other factors can be reasons why people do or do not frequently attend courses-for example, bad health (Yamashita et al., 2015; Kitiashvili and Tasker, 2016). Thus, the role of other factors hindering or promoting peoples' attendance in such courses, despite the role of individual motivations, has to be considered simultaneously.

One other study that does not rely on Houle's typology of motivations investigates personal motivation in the context of educational programs in Germany, finding distinct differences in the motivational characteristics between age groups (Leen and Lang, 2013). However, the study was strictly limited to information and communication technology (ICT) courses; thus, the focus was on a specific setting. Based on socioemotional selectivity theory (Carstensen, 1995; Carstensen et al., 1999), their main argument is that certain motivations are more prevalent in older adults (aged around 70 years old) than in younger people (aged around 26 years old) and vice versa because older adults experience time as being more limited; they find that certain motivations-such as belonging or personal growth-are more salient among older learners. With socioemotional selectivity theory (Carstensen, 1992), Leen and Lang (2013) used a theoretical framework that explicitly states that motivations in older learners are distinct from younger individuals. Nevertheless, it is uncertain whether these results can be generalized beyond the attendance of the courses that were the focus of Leen and Lang (2013) study. Thus, the question remains whether the same motivational structures are a driving force for attending classes or programs that can impart more general knowledge, as provided by SU programs. Furthermore, in previous studies, the differences in motivations are only compared between age groups (O'Connor, 1987; Leen and Lang (2013)) they are not investigated as distinct drivers for attendance in these types of programs. Finally, it is still uncertain if other factors hinder people from attending these programs.

Therefore, our study aims to extend the current body of research on the education of older adults by exploring the relationship between individual motivational structures and higher course attendance in the specific setting of the SU. Furthermore, the current study expands the literature by including measures that capture the (in-)capabilities regarding mobility, health, finances, and education. This is particularly interesting because with advancing age, these domains can become serious obstacles to attending classes, regardless of an individual's motivations. For example, as their mobility limitations increase, people face more difficulties managing daily tasks, such as riding a bus, going up and down stairs, and so forth (Rantakokko et al., 2013).

\section{THEORETICAL FRAMEWORK FOR MOTIVATIONS AND LEARNING IN THE LATER STAGES OF LIFE}

Because the educational attendance of older adults is clearly a product of multiple factors that can be allocated on different levels of abstraction-for example, micro-, meso-, and macrolevel (Boeren, 2017) -we focus solely on the individual level. At this level, scholars have argued-with differences in what they focus on-that motivations play a key role in an individual's decision to participate in educational programs. For example, Boeren et al. (2010) divide reasoning into internal motivation and external motivation, and Deci and Ryan (2004) find that motivations affect the decision-making process. However, in the case of the education of the adult learners, much of the literature is related to Boshier (1991) and, thus, to Houle (1961). Although the EPS has been used in various studies, the original typology of the motivational types of goal-oriented, activity-oriented, and learning-oriented types has been fairly criticized (Boshier and Collins, 1985). Further, these types of learners are very broad, are applicable to various educational activities throughout the life course of a person, and might change regarding the learning activity. Although this concept was designed to address different forms of learning (vocational and nonvocational), it does not focus on the specifics of the motivations regarding the learning of older adults (around and beyond the age of retirement) at the $\mathrm{SU}$.

According to socioemotional selectivity theory, social preferences-and, consequently, social behavior-are mitigated by underlying psychological processes that change as one grows older. As circumstances change in the different stages of life, the salience of basic goals and functions, which can be attained by social behavior, shifts over time (Carstensen, 1995). The main driver behind these changes is that the perceived limitedness of time (a person has to live) alters a person's preferences for goal attainment. Knowledge-based and competitive goals oriented 
more toward a job-related career are less important in the life phase after retirement, and emotion-related goals take center stage. In general, emotion-related goals promise more immediate satisfaction and short-term benefits. Leen and Lang (2013) translate this approach and combine the motives of learning with socioemotional needs; they identify four types of motivation-"belonging," "striving for personal growth," "instrumentality," and "competitiveness"-in their study of two ICT courses, and they identify that belonging and personal growth are the main motivations for older learners (Leen \& Lang, 2013, p. 975).

Personal growth refers to an intrinsic motivation of selfimprovement and self-efficacy. Thus, the knowledge/content that is learned has to have a strong connection to the individual's personality. Hence, learning is intrinsic but only for oneself, and it does not have further effects (Leen and Lang, 2013). As a motivation, belonging relies on the side effect of learning as a social activity. Learning activities often involve others; thus, they provide meaningful social contact outside one's environment. This social environment also allows for the possibility of competition-the third form of motivation. Competition is motivated by achievements and social comparison; this can either be inside a given learning environment or outside it with an individual's peers. Finally, the benefits from learning can be social, material, and individual. Therefore, the instrumentality of the consequences of learning can be the primary motivation.

Because Leen and Lang (2013) only look at the differences in motivations between age groups and how chronological age is related to one's motivational structure, the question whether these motivational structures are the general drivers behind engagement in education remains unanswered, so this must be empirically tested. Although this is one of the questions to be answered, there is also the question about which one of the motivations defined by Leen and Lang (2013) are the strongest drivers. One can argue with the underlying assumption regarding the perceived limitedness of time that some of these motivations lose their strength with proceeding age. As mentioned above, the short-term benefits should start to outweigh long-term effects. Hence, it can be argued that motivations of belonging tend to be directly related to a short-term reaction, especially regarding the specific nature of the SU. Belonging can be immediately satisfied by engaging in the SU and meeting with people with similar interests. However, so far, this has not been tested in an empirical study.

Although motivations theoretically do have an impact on educational engagement, it would be short-sighted to not consider other factors that might have an impact (Yamashita et al., 2015). A person's participation in education is still affected by social inequalities; this also holds true in old age after retirement (Bjursell et al., 2017; Boeren, 2017). The intersection between age and inequalities can lead to even more severe constraints regarding one's capabilities (Heap et al., 2017; Lu et al., 2019). From semester fees to public transportation, some costs are involved, and these costs can affect older people differently depending on their financial situation. This intersection of inequality partially explains the differences in the health of older people (Corna, 2013; Knöchelmann et al., 2019). In addition to economic restrictions, bad health prevents people from participating in these types of programs. Dietary choices are associated with selfperceived economic means (Jyväkorpi et al., 2019), and low socioeconomic status partially explains frailty in older adults (Warmoth et al., 2018) and is negatively associated with the perception of aging (Yaghoobzadeh et al., 2018). Although it is true that the constraints resulting from inequality and health also affect younger people, it is plausible that the effect on older people is more severe. Younger people have the prospect of equalizing their possible (financial) shortcomings later in life, but this is not the case for retired people. It can also be argued that the intersection of inequality and age affects women more than men. This is because in Switzerland, the majority of women that are retired today did not fully engage in the labor market; therefore, they only have a limited pension because of, for example, staying at home to care for their children. Moreover, women were not equally able to achieve the same education level as men. Furthermore, bad health in older adults is often a combination of losing various basic abilities, such as sight, hearing, and sense of balance, and an increase in their general vulnerability because of multimorbidity (Marengoni et al., 2011; Jindai et al., 2016); thus, health intersects with existing inequalities. In addition, research has shown that people who feel younger and have a positive perception of their own age are more motivated to invest in work tasks at an older age (Shane et al., 2019). Therefore, we assume that people's perceptions of their own age and capabilities can further hinder attendance in educational programs. Because they feel less capable of doing everyday chores, it can be that they do not see themselves able to or entitled to attend such courses and classes.

To analyze old people's engagement in education, one has to pay attention to the individual motivations, social inequalities, health-related circumstances, and other factors that might play a role. Thus, we believe that simultaneously looking at the combination of motivations and (in-)capabilities will provide new insights into why some people more frequently attend educational programs, such as the SU, in the later stages of their life. Here, the aim is to discuss actual attendance by older adults, not to explain general enrollment, per se. Toward this end, we theorize the following:

$\mathrm{H1}$ : The more prevalent a person's specific form of motivation (e.g., instrumental motivations) for learning is, the higher the frequency of attendance will be.

H2: Better health, mobility, self-concept, and other factors regarding dimensions (summarized under capabilities and resources) that can be impaired by advancing age lead to a higher frequency of attendance in educational programs.

H3: People with higher socioeconomic status will have a higher frequency of attendance in educational programs.

H4: Specific forms of motivation that are more salient in the later stages of life, namely the motivation of belonging, have a greater positive impact on the frequency of lecture attendance than other forms of motivation. 
TABLE 1 | Summary of the study sample from the SU.

\begin{tabular}{|c|c|c|c|}
\hline Feature & Category & $n$ & $\%$ (only valid cases) \\
\hline & Male & 398 & 49.8 \\
\hline & $60-69$ & 336 & 41,4 \\
\hline & $70-79$ & 364 & 44.9 \\
\hline & $80-89$ & 104 & 12.8 \\
\hline & $90-96$ & 4 & 0.5 \\
\hline & Secondary school (2) & 16 & 2.0 \\
\hline & Vocational school/apprenticeship (3) & 281 & 35.4 \\
\hline & High school (4) & 89 & 11.2 \\
\hline & Extended secondary level (e.g., & 226 & 28.5 \\
\hline & Technical school/teacher education) (5) & & \\
\hline & Tertiary education (6) & 179 & 22.6 \\
\hline & 8,001-10,000 CHF (5) & 166 & 21.53 \\
\hline & $>10,000 \mathrm{CHF}(6)$ & 132 & 17.12 \\
\hline
\end{tabular}

$C H F=$ the abbreviation for Swiss Francs, the currency of Switzerland.

\section{MATERIALS AND METHODS}

\section{Data}

The current study used unique data that were gathered in 2018 and that included information on 811 participants of the SU program at the University of Zurich and the ETH Zurich (UZH3), a program that provides nonformal education to senior citizens aged 60 years and older. The UZH3 provides lectures and special events (e.g., excursions) for its members. The content comes from a variety of disciplines and covers results from recent research conducted by scientists from both institutions. The annual fee is $120 \mathrm{CHF}$ (approximately 129 USD), and these lectures are held in one of the facilities of the University of Zurich, which can be accessed via public or private transportation and are accessible for people with physical disabilities. The lectures take place every week on Tuesday and Thursday afternoon from 2 p.m. to 4 p.m.

To ask all 2,942 members (to become a member and have the right to participate, the older people have to pay the abovementioned annual fee) of the UZH3 about their satisfaction with the offered talks and services of the UZH3, a standardized postal survey was conducted combined with an optional online survey (Seifert, 2019). These data contain comprehensive information on the participants' motivations, lecture attendance, satisfaction with the courses, and sociodemographic information. All members of the UZH3 were informed about the study by letter and asked to participate in the online questionnaire or to complete an attached printed version of the questionnaire. The response rate was $27.6 \%$ $(\mathrm{n}=811)$. Of the completed questionnaires, $26 \%$ were completed online. Therefore, the sample for the present study included 811 participants, with an average age of 72.95 years $(S D=6.27)$; here, $50.2 \%$ were female and $49.8 \%$ were male. Table 1 provides a more detailed description of the sample.

\section{VARIABLES \\ Dependent variable: Number of lectures attended}

As emphasized, the current study aimed to explain program attendance, not initial engagement in educational programs. Thus, only people who were already enrolled in the UZH3 are included in the data. The measure that captures program attendance the best is the number of attended lectures at the UZH3 over the past 12 months. The number of lectures attended ranged between 0 and 50; on average, a person attended a total of twelve lectures; the median was ten lectures ( $S D=10.89)$. Because there is no official record of attendance, this variable depends on self-reported statements.

\section{Independent variables}

Motivation: To investigate motivational differences in the lecture attendants, we used motivation-scale items that partially rely on the work of Leen and Lang (2013). In the survey, original questions (the original language of the questionnaire by Leen and Lang (2013) is German) were used with adaptions on the wording and the addition of new items. The appendix contains a comparison of the questionnaires, which were translated into English for the current paper. Following the approach of Leen and Lang (2013), we conducted a factor analysis to explore the dimensions of the motivational factors related to attending the UZH3 lectures. In total, we found a similar, but not exact, replication of the factors from the paper by Leen and Lang (2013). There are several reasons for this: one reason addresses the difference in educational activity and, thus, the samples that were used (SU vs. ITC course), another might be that there are cultural differences regarding educational engagement between older German and Swiss people, and the last one might 
TABLE 2 | Factor analysis results.

\begin{tabular}{|c|c|c|c|c|c|c|}
\hline Variable & Mean (SD) & $\begin{array}{l}\text { Factor1 } \\
\text { "Educational } \\
\text { motivations" }\end{array}$ & $\begin{array}{c}\text { Factor2 } \\
\text { "Social } \\
\text { motivations" }\end{array}$ & $\begin{array}{c}\text { Factor3 } \\
\text { "Instrumental } \\
\text { motivations" }\end{array}$ & $\begin{array}{c}\text { Factor4 } \\
\text { "General } \\
\text { motivations" }\end{array}$ & $\begin{array}{c}\text { Factor5 } \\
\text { "Academic } \\
\text { motivations" }\end{array}$ \\
\hline Self-realization through learning & $2.72(1.28)$ & 0.575 & 0.154 & 0.132 & 0.023 & -0.003 \\
\hline Search for inspiration & $3.37(1.20)$ & 0.628 & -0.009 & 0.070 & 0.056 & 0.115 \\
\hline Education on the tertiary level & $2.67(1.36)$ & 0.337 & 0.011 & 0.070 & -0.005 & 0.324 \\
\hline Expectation of family and friends & $1.62(0.89)$ & -0.023 & 0.573 & -0.007 & -0.009 & 0.127 \\
\hline Friends also join & $2.00(1.14)$ & 0.036 & 0.432 & -0.037 & 0.023 & 0.140 \\
\hline Show others my success & $1.58(0.89)$ & 0.044 & 0.872 & -0.034 & 0.000 & -0.026 \\
\hline Being better than peers & $1.68(0.99)$ & -0.055 & 0.767 & 0.057 & -0.018 & -0.027 \\
\hline Knowledge helps in daily life & $2.90(1.13)$ & 0.092 & 0.000 & 0.794 & -0.017 & -0.005 \\
\hline Knowledge will be helpful in the future & $3.19(1.06)$ & -0.038 & 0.006 & 0.821 & 0.0034 & 0.016 \\
\hline Joy of learning & $4.32(0.84)$ & 0.194 & -0.038 & -0.079 & 0.600 & 0.015 \\
\hline Improve general knowledge & $4.72(0.56)$ & -0.118 & -0.012 & 0.045 & 0.737 & 0.006 \\
\hline Useful leisure activity & $4.23(0.84)$ & 0.295 & 0.072 & -0.097 & 0.481 & 0.015 \\
\hline Keeping me mentally fit & $4.51(0.72)$ & 0.007 & 0.021 & 0.152 & 0.600 & 0.022 \\
\hline Speaking about trending topics & $3.9(1.04)$ & -0.088 & 0.118 & 0.123 & 0.2009 & 0.407 \\
\hline Take part in scientific discussions & $3.15(1.19)$ & 0.023 & 0.003 & -0.004 & -0.015 & 0.799 \\
\hline SS loadings & & 1.307 & 2.226 & 1.591 & 1.751 & 1.243 \\
\hline Proportion var & & 0.077 & 0.131 & 0.094 & 0.103 & 0.073 \\
\hline Cumulative var & & 0.077 & 0.208 & 0.302 & 0.405 & 0.477 \\
\hline Proportion explained & & 0.161 & 0.274 & 0.196 & 0.216 & 0.153 \\
\hline $\begin{array}{l}\text { Factor correlations: Educational } \\
\text { motivations }\end{array}$ & $\begin{array}{l}\text { Std.a: } \\
0.689\end{array}$ & 1.000 & - & - & - & - \\
\hline Social motivations & $\begin{array}{l}\text { Std.a: } \\
0.764\end{array}$ & 0.367 & 1.000 & - & - & - \\
\hline Instrumental motivations & $\begin{array}{l}\text { Std.a: } \\
0.809\end{array}$ & 0.320 & 0.404 & 1.000 & - & - \\
\hline General motivations & $\begin{array}{l}\text { Std.a: } \\
0.744\end{array}$ & 0.375 & 0.171 & 0.393 & 1.000 & - \\
\hline Academic motivations & $\begin{array}{l}\text { Std.a: } \\
0.608\end{array}$ & 0.461 & 0.383 & 0.428 & 0.359 & 1.000 \\
\hline
\end{tabular}

Notes: Factor loadings are displayed from a rotated matrix. Bold values reflect the factors.

lie in the slight differences in the questionnaires. Leen and Lang (2013) report that ten closed and one open item were used. In the present study, we use seventeen items for the explorative factor analysis.

Table 2 presents the factor analysis results. To some extent, this analysis suggests the use of different item combinations of motivations; thus, the labeling of the motivations only partially refers to the previous results reported by Leen and Lang (2013).

To calculate the factors, for all the items associated with a given factor, the mean was taken from the answers that all used the same Likert scale, where 1 is "Does not apply to me at all" and 5 is "Applies to me fully." The variables were not scaled because they share the same scale. The metrics from the factor analysis suggest that the obtained factors meet the common criteria (Kaiser and Rice, 1974; DeVellis, 2016). Only two variables, "Get to know interesting people" and "Want to make up for lost education," were dropped because their factor loadings were not sufficient to include them in any of the five factors. For the factor analysis, the R package "psych" was used (Revelle, 2018). The procedure that was used to determine the number of factors was Horn's "parallel," which resulted in five factors. We used a principal factor solution to extract the factors that have an "oblimin" rotation. The latter allows the axes to be at an oblique angle, thus relaxing the assumption of the orthogonality of the factors.
Capabilities and resources: From the perspective of capabilities, it is essential to check whether a person is suffering from one or more restrictions that will affect their capabilities. In short, the participants were asked to rate their subjective general quality of life (Mean $=5.49, \mathrm{SD}=0.64$ ), health $($ Mean $=4.98, \mathrm{SD}=0.82)$, memory $($ Mean $=4.97, \mathrm{SD}=0.76)$, mobility (Mean $=5.23, \mathrm{SD}=0.81$ ), and ability to cope with everyday life (Mean $=4.55, \mathrm{SD}=0.6)$, ranging from 1 "very bad" to 6 "very good." Because this is a subjective evaluation, it gives some insight into the participants' current situation. The variables were used separately to distinguish which aspect has smaller or larger effects on lecture attendance. The variables were not further recoded.

People's attitudes toward their own age: The data contain statements that express people's attitudes toward their own age given their subjective situation. We believe that a person's positive subjective evaluation of their own capabilities is crucial for the initial engagement in education in later life. The eight statements (I feel very independent in my private household; In everyday life I am very much dependent on the help of others; I feel fresh and full of life; I feel very old; I have all kinds of plans for the next few years; Sometimes, I feel left alone; In my life, there is more joy than sorrow; I can master most problems well by myself) are based on the attitudes toward the age scale from Riegel and Riegel (1960) and were recoded in such a way that for all the statements, 
high values resemble a person's positive evaluation of their own age. The scale ranges from 1 "Does not apply at all" to 5 "Entirely true." Then, the mean of these eight statements was calculated $($ Mean $=4.38, \mathrm{SD}=0.47$, std. Cronbach's alpha $=0.745)$

Socioeconomics: To control for socioeconomic differences, we included sex (female 50.2\%, male $=49.8 \%$ ), household income in $\mathrm{CHF}$ (including rent from pensions) as an ordinal variable with a bandwidth of $2000 \mathrm{CHF}$ ranging from $1=$ up to $2000 \mathrm{CHF}$ until $6=$ over $10,000 \mathrm{CHF}($ Mean $=4.07, \mathrm{SD}=1,28)$. Also, the highest educational degree was measured using an ordinal variable ranging from one to 6 (Mean $=4.33, \mathrm{SD}=1.24)$. Income and education were used as quasi-metric variables. The corresponding values and distributions are presented in Table $\mathbf{1}$.

Distance to venue: To include a control variable, we used the region where the participants lived (Agglomeration of Zurich = $34.3 \%$, other federal state $=22.3 \%$, other region from the federal state of Zurich $=14.1 \%$, Zurich (venue of UZH3) $=29.3 \%$ ).

\section{METHODS}

First, to determine the motivations, a factor analysis was conducted using the principal factor solution, which is reported above. Second, bivariate and multivariate regressions were used to assess the individual effect of the motivations on lecture attendance. First, for each of the motivations, a bivariate logistic regression was run, and it contained only the dependent variable "number of lectures attended" (recoded as a dummy variable; $0=$ no attended lectures, $1=$ one or more attended lectures) and one of the five types of motivation. In the next step, for each of the motivations, a multivariate logistic regression was run, including the dependent dummy variable, one of the five motivations, and the control variables (quality of life, memory, mobility, the ability to cope with everyday life, people's attitudes toward their own age, sex, age, household income, the highest educational degree, and the distance to the venue).

Second, for each of the motivations, a bivariate linear regression was run, which contained the dependent variable "number of lectures attended" (scale from 0 to 50) and one of the five motivations. Again, a multivariate linear regression was calculated with the dependent variable, one of the five motivations, and the same other independent variables as in the multivariate logistic regressions. Hence, the comparison of the bivariate and multivariate models works as a robustness test of the estimates. The comparison of the logistic and linear models shows whether there are substantial changes in the effects of motivations when one only looks at the difference between people who do not attend any class and those who do attend one or more classes and when the variable is introduced as a continuous one.

Finally, a linear model was run, using the metric dependent variable (number of lectures attended, scale from 0 to 50) and all the independent variables. Further, the variables for the hypothesis regarding the socioeconomic dimensions, the capabilities and resources, and the control variables were again tested separately. The observations were held constant for all regressions to provide comparability between the results.

\section{RESULTS}

First, linear and logistic bivariate regressions were conducted (see Figure 1). In the logistic regressions, the dependent variable-attended lectures-was recoded in a dummy variable so that the people who attended one or more lectures were in one group and those who did not attend a single class were in the other. For the bivariate logistic models $(\mathrm{N}=695)$, we found general, educational, and academic motivations resulted in a significant increase in the likelihood of attending at least one lecture (educational motivations $b=$ 0.69 , se $=0.28, p=0.014$; social motivations $b=0.37$, se $=0.21$, $p=0.07$; instrumental motivations $b=0.44$, se $0.25, p=0.08$; general motivations $b=0.64$, se $0.23, p=0.006$; academic motivations $b=0.51$, se $=0.20, p=0.011)$. The bivariate linear regression $(\mathrm{N}=695)$ (using the dependent variable "lectures" as a metric variable ranging from 0 to 50) results show that all the motivations significantly increased the number of attended lectures (educational motivations $b=2.77$, se $=0.74$, $p=0.0002$; social motivations $b=1.59$, se $=0.50, p=0.001$; instrumental motivations $b=2.83$, se $=0.59, p=0.00001$; general motivations $b=1.40$, se $=0.52, p=0.007$; academic motivations $b=1.18$, se $=0.50, p=0.018)$.

Additionally, we included the other independent variables mentioned above (people's attitudes toward their own age, quality of life, health, memory, coping with everyday life, education, income, sex, age and region) to run the multivariate logistic and linear regressions. For the logistic regressions $(\mathrm{N}=695)$, we found that academic, general, and educational motivations significantly increased the likelihood of attending one or more lectures (educational motivations $b=0.37$, se $=0.16, p=0.023$; social motivations $b=0.35$, se $=0.18, p=0.051$; instrumental motivations $b=0.33$, se $=0.19, p=0.071$; general motivations $b=0.54$, se $=0.19, p=0.005$; academic motivations $b=0.57$, se $=$ $0.18, p=0.002$ ). However, when the dependent variable was used in its metric form, we found that all the motivations had a positive significant impact on the total number of attended lectures (educational motivations $b=1.67$, se $=0.42, p=0.0001$; social motivations $b=1.39$, se $=0.43, p=0.001$; instrumental motivations $b=2.0$, se $=0.41, p=0.00001$; general motivations $b=1.22$, se $=0.42$, $p=0.004$; academic motivations $b=1.30$, se $=0.43, p=0.003$ ).

Next, stepwise regressions were used to a) compare the strength of the different motivations in one model and b) compare the motivations to the sociodemographic and capabilities/resources variables and control variables. For these regressions, the dependent variable was used in its metric form, ranging from 0 to $50(\mathrm{~N}=695)$. The results presented in Table 3 show that neither the sociodemographic variable nor the capabilities/resources variable can explain a significant part of the variance. The control variable-where people lived compared with the venue of the SU-shows that the people living in another federal state of Switzerland attended a significantly fewer number of lectures $(b=-2.67$, se $=1.14, p=0.019)$. The people in the other categories-living in Zurich or in another region of the Canton of Zurich-also seemed to attend fewer lectures than the people living in the agglomeration of Zurich, but the difference is not significant. In the full model, we see that only instrumental 


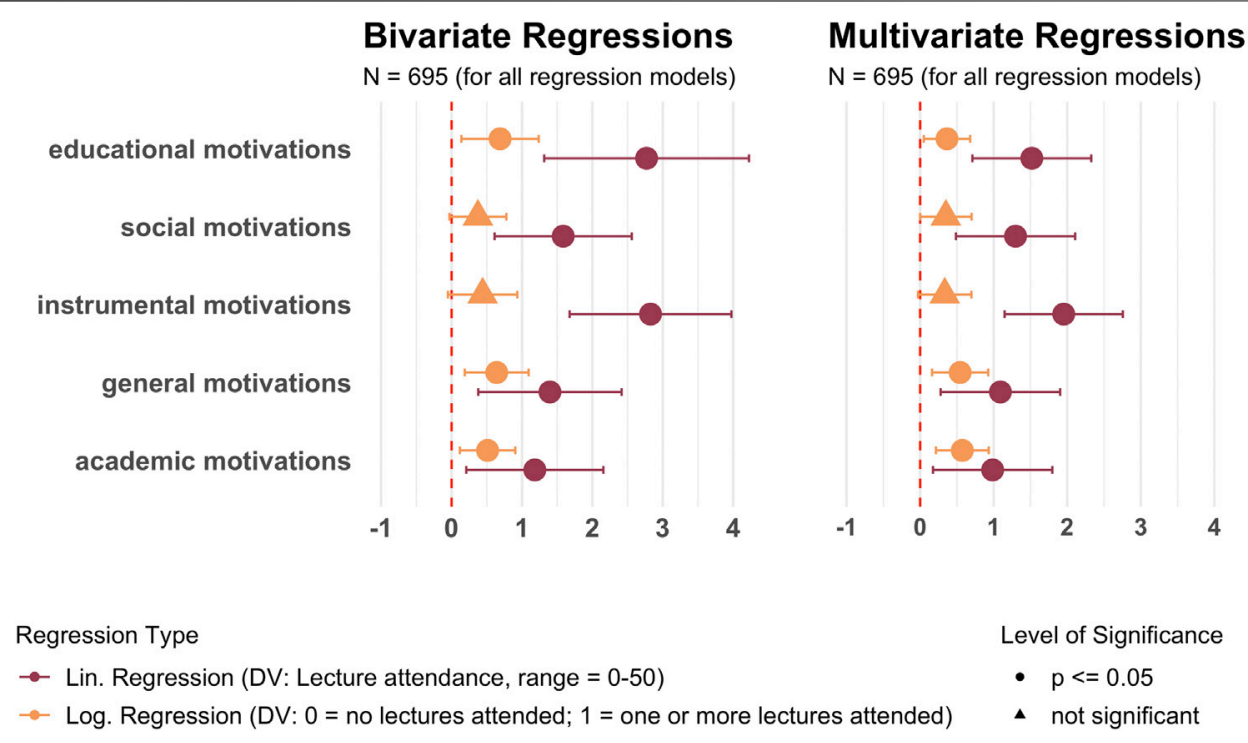

FIGURE 1 | Plot of the bi- and multivariate regressions.

TABLE 3 | Stepwise Regression.

\begin{tabular}{|c|c|c|c|c|c|c|c|c|c|c|c|c|}
\hline \multirow{2}{*}{$\begin{array}{l}\text { Dependent } \\
\text { variable } \\
\text { Predictors }\end{array}$} & \multicolumn{3}{|c|}{ Number of lectures attended } & \multicolumn{3}{|c|}{$\begin{array}{c}\text { Number of lectures } \\
\text { attended }\end{array}$} & \multicolumn{3}{|c|}{$\begin{array}{c}\text { Number of lectures } \\
\text { attended }\end{array}$} & \multicolumn{3}{|c|}{$\begin{array}{c}\text { Number of lectures } \\
\text { attended }\end{array}$} \\
\hline & Estimates & $\begin{array}{l}\text { Std. } \\
\text { Error }\end{array}$ & $p$ & Estimates & $\begin{array}{l}\text { Std. } \\
\text { Error }\end{array}$ & $p$ & Estimates & $\begin{array}{l}\text { Std. } \\
\text { Error }\end{array}$ & $p$ & Estimates & $\begin{array}{l}\text { Std. } \\
\text { Error }\end{array}$ & $p$ \\
\hline (Intercept) & 10.91 & 8.31 & 0.190 & 8.35 & 4.55 & 0.067 & 14.33 & 5.51 & 0.010 & 13.47 & 0.70 & $<0.001$ \\
\hline Educational motivations & 0.75 & 0.52 & 0.147 & & & & & & & & & \\
\hline Social motivations & 0.19 & 0.56 & 0.729 & & & & & & & & & \\
\hline Instrumental motivations & 1.45 & 0.55 & 0.009 & & & & & & & & & \\
\hline General motivations & -0.17 & 0.56 & 0.763 & & & & & & & & & \\
\hline Academic motivations & 0.38 & 0.50 & 0.445 & & & & & & & & & \\
\hline $\begin{array}{l}\text { People's attitudes toward } \\
\text { their own age }\end{array}$ & 0.50 & 1.18 & 0.670 & 0.99 & 1.18 & 0.398 & & & & & & \\
\hline Quality of life & -0.50 & 0.87 & 0.567 & -0.48 & 0.87 & 0.577 & & & & & & \\
\hline Health & -0.46 & 0.64 & 0.477 & -0.55 & 0.64 & 0.393 & & & & & & \\
\hline Memory & 0.58 & 0.62 & 0.352 & 0.63 & 0.62 & 0.306 & & & & & & \\
\hline Mobility & 0.06 & 0.71 & 0.936 & 0.15 & 0.70 & 0.833 & & & & & & \\
\hline Coping with everyday life & 0.57 & 0.97 & 0.557 & 0.25 & 0.97 & 0.796 & & & & & & \\
\hline Education & 0.21 & 0.36 & 0.561 & & & & 0.18 & 0.36 & 0.611 & & & \\
\hline Income & -0.14 & 0.36 & 0.688 & & & & -0.15 & 0.35 & 0.668 & & & \\
\hline Sex (male) & 2.23 & 0.92 & 0.016 & & & & 1.43 & 0.90 & 0.115 & & & \\
\hline Age & -0.03 & 0.07 & 0.719 & & & & -0.04 & 0.07 & 0.566 & & & \\
\hline Other canton* & -3.49 & 1.14 & 0.002 & & & & & & & -2.67 & 1.14 & 0.019 \\
\hline $\begin{array}{l}\text { Other region from the } \\
\text { canton* }\end{array}$ & -0.79 & 1.31 & 0.543 & & & & & & & -1.09 & 1.30 & 0.402 \\
\hline Zurich City ${ }^{*}$ & -0.85 & 1.06 & 0.421 & & & & & & & -1.17 & 1.04 & 0.261 \\
\hline Observations & 695 & & & 695 & & & 695 & & & 695 & & \\
\hline$R^{2} / R^{2}$ adjusted & 0.058/0.033 & & & $0.004 /-0.004$ & & & $0.005 /-0.001$ & & & $0.008 / 0.004$ & & \\
\hline
\end{tabular}

Notes: * $=$ ref. Agglomeration of Zurich.

motivations have a significant impact on lecture attendance $(b=$ 1.45 , se $=0.55, p=0.009$ ). Moreover, in the full model, being male is significantly positively $(b=2.23$, se $=0.92, p=0.016)$ associated with lecture attendance, and living in another federal state is significantly negatively $(b=-3.49$, se $=1.14, p=0.002)$ associated with lecture attendance. 


\section{DISCUSSION}

The results from the various regressions show that individual motivational structures are very important for lecture attendance at the SU. This becomes even more prominent when the results from the logistic and linear regressions are compared. In the bivariate models, all the motivations significantly affect the likelihood of attending at least one lecture, except for social and instrumental motivations. Furthermore, all types of motivation significantly increase the total number of lectures attended. Hence, one could assess that motivations have to be carefully addressed when the goal is to maximize people's lecture attendance at the SU. To strengthen the role that motivations play regarding lecture attendance, the multivariate regressions function as a robustness test of the initial findings and are tested against a fairly large sample. Thus, although changes between the bivariate and multivariate regressions are not surprising, we do only find changes in the coefficients, but the significance of the motivations remains stable. The insignificance of social and instrumental motivations occurring in the logistic models indicates that the effect of these two variables lies in the variance of people attending more than one lecture. Therefore, the findings support $\mathrm{H} 1$, showing that greater individual motivations lead to higher lecture attendance.

For $\mathrm{H} 2$ and $\mathrm{H} 3$, the results from the stepwise regressions show that the dimensions regarding capabilities and resources, attitudes about one's own age, and socioeconomic factors do not have a substantial influence on lecture attendance. Hence, these two hypotheses are rejected. This might be an artifact of the participants' beliefs about their health, mobility, education, and financial situation when making the decision to enroll in the SU. Thus, people who perceive their own mobility, health, and so forth as insufficient to attend the SU do not enroll in the first place, so they did not participate in this survey. Hence, although the people who are enrolled vary in terms of these dimensions, that variation does not have a significant effect on their lecture attendance. It has to be stressed once more that the SU participants are a specific group and that the empirical data are limited to participants. Hence, it cannot be claimed that these variables do not influence people's attendance (or at least enrolment) in the SU. Also, one might consider that attendance has an effect on the various health-related characteristics of people found by other researchers (Mitchell et al., 1997; Zielińska-Więczkowska et al., 2011; Yamashita et al., 2019).

Furthermore, in the full model, no differences were observed in the significance of these variables, except for the sex of the participants, which was significant. In general, men attend more lectures than women. Thus, it seems that the lecture attendance behavior of people with a low income, poorer health, lower overall quality of life, negative subjective feelings about age, decreased mobility, and lower education attainment is similar to people with a high income, good health, high overall quality of life, high education level, and so forth. Therefore, we speculate that individual preferences regarding the format and topic of the lecture are responsible for the actual difference in attendance. Also, one might consider that the $\mathrm{SU}$ is a very specific educational program delivered by universities-it was more likely to be attended by men in the cohort under study-which might explain the difference in attendance by the sex variable. Further, this is contrary to the findings of Williamson (2000), for example, who finds that women in general are more likely to participate in lifelong learning activities in the SU.

Finally, H4-stating that certain motivations affect lecture attendance more than others-was tested in the full model. We found that only instrumental motivations remained significant. Thus, the people motivated by using the obtained knowledge immediately or in the future are those who most often attend classes. This is in line with Leen and Lang (2013), who find that from the perspective of socioemotional selectivity theory, the motivations that promise immediate goal attainment are those that should be more salient in older adults. This might correlate with the subjects the individuals are interested in. For example, the people motivated by learning skills will enroll in courses that are more frequently held because to learn skills, one needs time to practice and improve; however, this cannot be tested with the data used in the current study.

Age was not found to influence lecture attendance. As highlighted in socioemotional selectivity theory, with advancing age, a person's goals shift toward more immediate satisfaction and utility. In your study, we found no age effect on the frequency of lecture attendance. However, our study included only a portion of the older population already used to the $\mathrm{SU}$, and we do not have longitudinal data. Therefore, future studies with a longitudinal method should investigate whether there are agerelated effects of changing motivations in lecture attendance.

The proximity of people's residence to the UZH3 venue significantly affected the overall lecture attendance $(b=-3.027$, se $=1.158, p=0.009$ ). The need to travel to UZH3 from another federal state reduced the total number of attended lectures. This is not surprising; it means that a person's travel time and effort are increasing substantially. Thus, we think that lecture attendance is also affected by the economy of time. Consequently, through the progressing perception of time as a limited good, time itself will be more carefully spent. These findings are in line with other research regarding older learners in general (Lamb and Brady, 2005). Nevertheless, in addition to travel time, we would suggest that mobility restrictions occurring in old age can be barriers to their involvement in senior university lectures. However, we cannot test this with our data because we focus only on participants already using the senior university. We believe more studies are needed with different samples of participants (non-users and users of senior university lectures).

\section{Limitations}

Because the sample only consisted of people already engaged in activities at the SU, it is not representative of older adults who are not visiting the SU. Hence, the results have to be viewed carefully. However, the empirical material on many of the participants is a fairly large sample for this cohort. Some factors-which are already included in the analysis-might contribute to people engaging in activities at the $\mathrm{SU}$ in the first place. It is even more likely that factors, such as some form of multimorbidity (Marengoni et al., 2011; Jindai et al., 2016), compel those people to drop out of the sample either at the initial engagement stage or if progressing age causes them to resign from the SU. 
All the information is self-reported, and no additional information was added from any other sources. Because this gives detailed insights into the participants of the SU, it has to be mentioned that classical methodological survey problems, such as the social desirability bias or the correlation of nonresponse within specific subgroups of the sample, cannot be ruled out and remain a potential limitation of the empirical data.

One other limitation regarding the comparison with the former study by Leen and Lang (2013) and this work is also related to the samples. In the study of Leen and Lang (2013), the sample consisted of older and younger adults enlisted in an ICT course in Germany, which is a specific topic, whereas the current study used a sample of people who were enrolled in the SU of Zurich, which provides a variety of courses, topics, and interests. Further, one could also argue that there might be cultural differences regarding engaging in educational activities between the two countries and that the SU-because it takes place in the university-has the potential to attract or deter specific groups of this heterogenous population of older learners.

As mentioned above, some variables that could account for the differences in lecture attendance are lacking in the analysis. First, one would need some indicator that represents the interests of a person and how these overlap with the actual courses provided by the SU in the given time period. Additionally, there should be an indicator that represents the compliance of the provided formats of the SU with the requested formats (e.g., lectures, online courses, or excursions).

Finally, the explanatory power (which reflects the proportion of the total variance in the dependent variable that can be explained by the independent variables) of the models is very small. This is because of the psychological process of number representation, which affects the dependent variable of the analysis: "How many lectures did you attend in the past 6 months?" In a well-tested phenomenon, when people have to generate a "random number" within a sequence, some values are much more likely to occur in total (Towse et al., 2014). We strongly believe that the people who were uncertain of the exact number of times they attended a lecture of the SU were a) slightly more likely to state odd numbers (66.7\%) and b) clearly more likely to state numbers that can be divided by five (42.9\%), where the minimum is 0 attended lectures and the maximum is 50 attended lectures. This affects the efficiency of the estimated parameters, especially the proportion of the explained variance. This introduces "noise" into the data because the stated values do not reflect actual attendance in all cases. We do not believe that people have a tendency to over- nor underestimate; hence, there is no specific bias introduced into the model. For this noise, the observed and expected values result in larger residual variance, whereupon the R2 metric is calculated and, thus, the explained variance in the residual is low.

\section{CONCLUSION}

The analysis reveals that internal motivations are key factors that can explain higher lecture attendance at the SU. However, the explanatory power is limited because of the restrictions given by the dependent variable. This shows that the uniqueness of the motivational characteristics of older people is one aspect that should be considered when thinking about meeting their educational needs for lifelong learning shortly before and after they retire.

In turn, this new information can enable policy makers and institutions to provide courses that meet these criteria. This is important for any form of vocational education, not just courses for older adults. Because this population group that is more vulnerable to social isolation (Nicholson, 2012), cognitive impairments (Plassman et al., 2008), and age discrimination (Stokes and Moorman, 2016), these types of educational programs provide older adults with the possibility of strengthening their skills, maintaining and extending their social contacts, and enhancing their feeling of being a vital part of society. Proximity to the venue in which the courses are offered is one factor that seems to be crucial for lecture attendance. Thus, if the programs in question are only provided by universities, many people will encounter long traveling times, requiring more effort to attend classes and, hence, potentially causing people to drop out of these programs.

With respect to the data, the special characteristics of the SU, and the aim of the current paper, we only looked at which motivations can account for higher attendance in the SU. It is important to note that one would need a data set that also contains individuals not enrolled in educational programs to fully test the hypotheses and draw more conclusive findings. In addition, one might argue that the specific characteristics of the SU diverge from other nonformal educational programs that target older learners. Hence, changes in the findings would not be surprising. Further research should also explore the role of the constraints and motivations regarding initial enrollment, and more research should be done to investigate the long-term effects of such educational programs on, for example, people's subjective feelings about their own age or their feelings about belonging to society.

\section{DATA AVAILABILITY STATEMENT}

The raw data supporting the conclusions of this article will be made available by the authors, without undue reservation.

\section{ETHICS STATEMENT}

The studies involving human participants were reviewed and approved by the Ethics Committee of the Faculty of Arts and Social Sciences, University of Zurich. The patients/participants provided their written informed consent to participate in this study.

\section{AUTHOR CONTRIBUTIONS}

The questionnaire and the data collection were done by AS. The analysis was conducted and the text in the manuscript written by TA and AS. 


\section{REFERENCES}

BFS (2016). Weiterbildung in der Schweiz 2016 Kennzahlen aus dem Mikrozensus Aus- und Weiterbildung. [Further education in Switzerland 2016 Key figures from the microcensus Education and training]. Available at: https://www.bfs.admin. $\mathrm{ch} / \mathrm{bfs} / \mathrm{de} / \mathrm{home} / \mathrm{statistiken/bildung-wissenschaft/weiterbildung.assetdetail.}$ 3722515.html (Accessed October 10, 2020).

Bjursell, C., Nystedt, P., Björklund, A., and Sternäng, O. (2017). Education level explains participation in work and education later in life. Educ. Gerontol. 43, 511-521. doi:10.1080/03601277.2017.1357397

Boeren, E. (2017). Understanding adult lifelong learning participation as a layered problem. Stud. Contin. Educ. 39 (2), 161-175. doi:10.1080/0158037X.2017. 1310096

Boeren, I., and Baert, H. (2010). Theoretical models of participation in adult education: the need for an integrated model. Int. J. Lifelong Educ. 29 (1), 45-61. doi:10.1080/02601370903471270

Boshier, R., and Collins, J. B. (1985). The Houle typology after twenty-two years: a large-scale empirical test. Adult Educ. Q. 35, 113-130. doi:10.1177/ 0001848185035003001

Boshier, R. (1991). Psychometric properties of the alternative form of the education participation scale. Adult Education Q. 41, 150-167. doi:10.1177/ 0001848191041003002

Carstensen, L. L., Isaacowitz, D. M., and Charles, S. T. (1999). Taking time seriously. A theory of socioemotional selectivity. Am. Psychol. 54 (3), 165-181. doi:10.1037/0003-066X.54.3.16510.1037//0003-066x.54.3.165

Carstensen, L. L. (1995). Evidence for a life-span theory of socioemotional selectivity. Curr. Dir. Psychol. Sci. 4 (5), 151-156. doi:10.1111/1467-8721. ep11512261

Carstensen, L. L. (1992). Social and emotional patterns in adulthood: support for socioemotional selectivity theory. Psychol. Aging. 7, 331-338. doi:10.1037/08827974.7.3.33110.1037//0882-7974.7.3.331

Chan, M. Y., Haber, S., Drew, L. M., and Park, D. C. (2016). Training older adults to use tablet computers: does it enhance cognitive function? Gerontologist. 56 (3), 475-484. doi:10.1093/geront/gnu057

Clare, L., and Woods, R. T. (2004). Cognitive training and cognitive rehabilitation for people with early-stage Alzheimer's disease: a review. Neuropsychol. Rehabil. 14 (4), 385-401. doi:10.1080/09602010443000074

Corna, L. M. (2013). A life course perspective on socioeconomic inequalities in health: a critical review of conceptual frameworks. Adv. Life Course Res. 18 (2), 150-159. doi:10.1016/j.alcr.2013.01.002

Deci, E. L., and Ryan, R. M. (2004). Handbook of self-determination research. New York, NY: University Rochester Press.

DeVellis, R. F. (2016). Scale development: Theor. Appl., California: Sage Publications, Inc. 2nd Edn. 26.

Formosa, M. (2014). Four decades of Universities of the Third Age: past, present, future. Ageing Soc. 34 (1), 42-66. doi:10.1017/S0144686X12000797

Formosa, M. (2019). The University of the third age and active ageing: European and Asian-Pacific perspectives. Cham: Springer Nature Switzerland AG.

Hammond, C. (2004). Impacts of lifelong learning upon emotional resilience, psychological and mental health: fieldwork evidence. Oxford Rev. Educ. 30, 551-568. doi:10.1080/0305498042000303008

Hayward, M. D., Hummer, R. A., and Sasson, I. (2015). Trends and group differences in the association between educational attainment and U.S. adult mortality: implications for understanding education's causal influence. Soc. Sci. Med. 127, 8-18. doi:10.1016/j.socscimed.2014.11.024

Heap, J., Fors, S., and Lennartsson, C. (2017). Coexisting disadvantages in later life: demographic and socio-economic inequalities. J. Popul. Ageing. 10 (3), 247-267. doi:10.1007/s12062-016-9158-y

Houle, C. O. (1961). Inquiring mind: a study of the adult who continues to learn. Platteville, US: Univ. Wisconsin.

Jenkins, A., and Mostafa, T. (2015). The effects of learning on wellbeing for older adults in England. Ageing Soc. 35, 2053-2070. doi:10.1017/S0144686X14000762

Jindai, K., Nielson, C. M., Vorderstrasse, B. A., and Quiñones, A. R. (2016). Multimorbidity and functional limitations among adults 65 or older, NHANES 2005-2012. Prev. Chronic Dis. 13, E151. doi:10.5888/pcd13. 160174
Jyväkorpi, S. K., Urtamo, A., and Strandberg, T. E. (2019). Self-perception of economic means is associated with dietary choices, diet quality and physical health in the oldest old men from the highest socioeconomic group. J. Nutr. Health Aging. 23 (1), 60-62. doi:10.1007/s12603-018-1102-9

Kaiser, H. F., and Rice, J. (1974). Little jiffy, mark IV. Educ. Psychol. Meas. 34 (1), 111-117. doi:10.1177/001316447403400115

Kim, A., and Merriam, S. B. (2004). Motivations for learning among older adults in a learning in retirement institute. Educ. Gerontol. 30, 441-455. doi:10.1080/ 03601270490445069

Kitiashvili, A., and Tasker, P. B. (2016). The relationship between attitudes, motives and participation of adults in continuing education: the case of Georgia. Int. J. Res. Rev. Educ. 2020, 13-21.

Knapper, C., and Cropley, A. J. (2000). Lifelong learning in higher education. London,UK: Kogan Page Limited.

Knöchelmann, A., Günther, S., Moor, I., Seifert, N., and Richter, M. (2019). Social mobility, accumulation of disadvantages and health. An analysis with retrospective data from the GSOEP (2002-14). Eur. J. Public Health. 30 (1), 98-104. doi:10.1093/eurpub/ckz128

Lamb, R., and Brady, E. M. (2005). Participation in lifelong learning institutes: what turns members on? Educ. Gerontol. 31, 207-224. doi:10.1080/03601270590900936

Leen, E. A. E., and Lang, F. R. (2013). Motivation of computer-based learning across adulthood. Comput. Hum. Behav. 29 (3), 975-983. doi:10.1016/j.chb. 2012.12.025

Lin, Y.-Y. (2020). Support matters: predictors of intrinsic motivation in older learners in Taiwan. Aust. J. Adult Learn. 60, 24.

Lu, W., Pikhart, H., and Sacker, A. (2019). Comparing socio-economic inequalities in healthy ageing in the United States of America, England, China and Japan: evidence from four longitudinal studies of ageing. Ageing Soc. 1-26. doi:10. 1017/S0144686X19001740

Marengoni, A., Angleman, S., Melis, R., Mangialasche, F., Karp, A., Garmen, A., et al. (2011). Aging with multimorbidity: a systematic review of the literature. Ageing Res. Rev. 10 (4), 430-439. doi:10.1016/j.arr.2011.03.003

Mitchell, R. A., Legge, V., and Sinclair-Legge, G. (1997). Membership of the university of the third age (U3A) and perceived well-being. Disabil. Rehabil. 19, 244-248. doi:10.3109/09638289709166534

Narushima, M., Liu, J., and Diestelkamp, N. (2018). Lifelong learning in active ageing discourse: its conserving effect on wellbeing, health and vulnerability. Ageing Soc. 38, 651-675. doi:10.1017/S0144686X16001136

Narushima, M., Liu, J., and Diestelkamp, N. (2013). The association between lifelong learning and psychological well-being among older adults: implications for interdisciplinary health promotion in an aging society. Activities, Adaptation \& Aging. 37, 239-250. doi:10.1080/01924788.2013.816834

Nicholson, N. R. (2012). A review of social isolation: an important but underassessed condition in older adults. J. Prim. Prev. 33 (2-3), 137-152. doi:10.1007/s10935-012-0271-2

O'Connor, D. M. (1987). Elders and higher education: instrumental or expressive goals? Educ. Gerontol. 13 (6), 511-519. doi:10.1080/0360127870130607

Park, D. C., Gutchess, A. H., Meade, M. L., and Stine-Morrow, E. A. (2007). Improving Cognitive function in older adults: nontraditional approaches. J. Gerontol. B Psychol. Sci. Soc. Sci. 62, 45-52. doi:10.1093/geronb/62.special_issue_1.45

Plassman, B. L., Langa, K. M., Fisher, G. G., Heeringa, S. G., Weir, D. R., Ofstedal, M. B., et al. (2008). Prevalence of cognitive impairment without dementia in the United States. Ann. Intern. Med. 148 (6), 427-434. doi:10.7326/0003-4819-1486-200803180-00005

Rantakokko, M., Mänty, M., and Rantanen, T. (2013). Mobility decline in old age. Exerc. Sport Sci. Rev. 41 (1), 19-25. doi:10.1097/JES.0b013e3182556f1e

Revelle, W. (2018). Psych: procedures for personality and psychological research. Evanston, IL: Northwestern University. Available at: https:/CRAN.R-project. org/package $=$ psych Version $=1.8 .12$.

Riegel, K. F., and Riegel, R. M. (1960). A study on changes of attitudes and interests during later years of life. Vita Hum. Int. Z. Lebensalterforsch. 3 (4), 177-206. doi:10.1159/000269403

Seifert, A. (2019). Senioren-Universität zürich: befragung der Teilnehmenden. PsyArXiv. doi:10.31234/osf.io/z5v8p

Shane, J., Hamm, J., and Heckhausen, J. (2019). Subjective age at work: feeling younger or older than one's actual age predicts perceived control and motivation at work. Work, Aging and Retirement 5, 323-332. doi:10.1093/ workar/waz013 
Stokes, J. E., and Moorman, S. M. (2016). Who are the people in your neighborhood? Neighborhood age composition and age discrimination. Soc. Psychol. Q. 79 (1), 68-80. doi:10.1177/0190272515626569

Tabatabaei, S. M., and Roostai, F. (2014). University of the third age: a unique model for successful implementation of "active ageing. Health Scope. 3, e93540. doi:10.17795/jhealthscope-18297

Towse, J. N., Loetscher, T., and Brugger, P. (2014). Not all numbers are equal: preferences and biases among children and adults when generating random sequences. Front. Psychol. 5, 19-27. doi:10.3389/fpsyg.2014.00019

Vaportzis, E., Martin, M., and Gow, A. J. (2017). A tablet for healthy ageing: the effect of a tablet computer training intervention on cognitive abilities in older adults. Am. J. Geriatr. Psychiatry 25 (8), 841-851. doi:10.1016/j.jagp.2016. 11.015

Warmoth, K., Tarrant, M., Abraham, C., and Lang, I. A. (2018). Relationship between perceptions of ageing and frailty in English older adults. Psychol. Health Med. 23 (4), 465-474. doi:10.1080/13548506.2017.1349325

Williamson, A. (2000). Gender issues in older adults' participation in learning: viewpoints and experiences of learners in the university of the third age (U3A). Educ. Gerontol. 26, 49-66. doi:10.1080/036012700267394

Yaghoobzadeh, A., Sharif Nia, H., Pahlevan Sharif, S., Hosseinigolafshani, S. Z., Mohammadi, F., Oveisi, S., et al. (2018). Role of sex, socioeconomic status, and emotional support in predicting aging perception among older adults. Int. J. Aging Hum. Dev. 87 (1), 77-89. doi:10.1177/0091415017727211
Yamashita, T., Bardo, A. R., Liu, D., and Yoo, J. W. (2019). Education, lifelong learning and self-rated health in later life in the USA. Health Educ. J. 78, 328-339. doi:10.1177/0017896918809500

Yamashita, T., López, E. B., Keene, J. R., and Kinney, J. M. (2015). Predictors of adult education program satisfaction in urban community-dwelling older adults. Educ. Gerontol. 41, 825-838. doi:10.1080/03601277.2015. 1050909

Zielińska-Więczkowska, H., Kędziora-Kornatowska, K., and Ciemnoczołowski, W. (2011). Evaluation of quality of life (QoL) of students of the University of Third Age (U3A) on the basis of socio-demographic factors and health status. Arch. Gerontol. Geriatr. 53, e198-e202. doi:10.1016/j.archger.2010. 09.003

Conflict of Interest: The authors declare that the research was conducted in the absence of any commercial or financial relationships that could be construed as a potential conflict of interest.

Copyright (c) 2021 Ackermann and Seifert. This is an open-access article distributed under the terms of the Creative Commons Attribution License (CC BY). The use, distribution or reproduction in other forums is permitted, provided the original author(s) and the copyright owner(s) are credited and that the original publication in this journal is cited, in accordance with accepted academic practice. No use, distribution or reproduction is permitted which does not comply with these terms. 
APPENDIX

Comparison of the motivation questions between our study and Leen and Lang (2013)

Our Study

I participate because...

... I enjoy learning

... I see learning as a meaningful leisure activity

... I want to show others that I am capable of learning successfully

... I want to do well compared to my peers

... What I have learned helps me to cope with everyday tasks

... What l've learned will be useful in the future

... I want to expand my general knowledge

... My personal environment expects me to continue my education

... I want to participate in discussions on current scientific topics

... I am in search of new inspiration/stimulation

... I find it important to have a say in current affairs

... My friends also participate in the educational opportunities

... I want to realize myself through learning

... I want to keep myself mentally fit

... I want to continue my education at the university level
Leen and Lang (2013)

I learn for the joy of learning

I see learning as a meaningful leisure activity

I want to show others that I am able to learn/study successfully

I want to do well in comparison to my peers

What I have learned helps me cope with everyday tasks

In the future, what I have learned will be useful

I want to expand my general knowledge

My personal environment expects me to continue my education

I want to participate in discussions on current topics

I am in search of new inspiration/stimulation 